\title{
INCLUSIVE TEAMWORK DESIGN WITHIN A FIRST YEAR ENGINEERING COURSE
}

\author{
Amber Monteiro, Sandra Monteiro and Kim S. Jones \\ McMaster University \\ monteira@mcmaster.ca, monteisd@mcmaster.ca, kjones@mcmaster.ca
}

\begin{abstract}
Unless we intentionally design teamwork practices within engineering courses, there will be inequity in learning outcomes linked to students' identity (e.g. specific cultures and gender). In this study we aim to address the inequity of learning outcomes for woman engineering students in a first-year project-based course. We provide evidence that supports this goal and describe four literature-driven best practices for improving teamwork practices:

1.Technical and non-technical roles will rotate.

2.Groups will be assigned and will be constrained to not have a gender-solo student.

3.Low-stakes, technically oriented icebreakers will accelerate trust-building.

4.Teams of students will receive formative feedback on team effectiveness, function and inclusivity.
\end{abstract}

Keywords: Teamwork, inclusion, gender, project-based learning

\section{INTRODUCTION}

There is an increasing emphasis on teamwork in engineering education. As we design team experiences, we must consider whether all students have access to an equitable experience. Conceptually, we believe that inclusive teamwork structures in course design can mitigate many inequities. In our framework, we use the literature to understand how gender inequities are likely to intersect teamwork experiences, then explore which literature-based teamwork interventions can be used to mitigate these inequities. We focus our work on a new firstyear design course but believe that the approaches described are broadly applicable within engineering education.

Just as folks seek homophily in society [1], engineering students often form groups along culture or gender lines [2]. Students that represent a minority proportion of a team, within a project-based context, experience inequity in learning outcomes and the division of labour [3], [4]. When woman engineering students compose the minority of a team they are: 1) more likely to end up with more communications-rich roles [3]; 2) less likely to seek feedback [5] and 3) may be excluded from collaboration as the "solo" woman [4]. Left unchecked these inequities can persist even into professional careers [6].

Prior research has shown that we must intentionally design teamwork practices within engineering courses to create equitable learning outcomes [7]. We describe four literature-driven best practices that we are implementing in a first-year course to ensure that all genders of students experience equally positive and effective learning. We recognise that not all students identify within the gender binary and that other, often intersecting, aspects of identity are likely to lead to inequities [8]. However, for the purpose of introducing a program wide intervention, we are focusing on these two identities.

\section{EDUCATIONAL CONTEXT}

The Faculty of Engineering at McMaster University is redesigning its curriculum to include more experiential learning as a mechanism to teach technical concepts (the Pivot). McMaster Engineering has a common first year, with nearly 1000 students. We have combined four separate engineering courses in our common first year into one, 13-unit, year-long course that has four projects, done sequentially: Sprint projects. Because these projects will all be team-based, we were highly motivated to implement research-based teamwork best practices.

Sprint projects take 6-8 weeks and will become progressively more student-driven through the year. Typical of any undergraduate engineering program [9], students at McMaster University will also be expected to manage a challenging course load. The first-year curriculum includes three lecture hours per week, one twohour design studio (with 40 students) and two three-hour labs (with 80 students). In our program, they will have four additional courses per term. The Sprint projects will be done in teams of four and are intended to cover material that was previously covered in courses titled Structure and Properties of Materials, Engineering Design and Graphics, 
Engineering Computation, and Engineering Profession and Practice.

Although project-based learning is an effective way of fostering student learning [10]-[14], it has rarely been implemented at the scale we propose. We need to ensure that all the students become proficient at all the technical content, so they are prepared for their future studies. However, the pressure to perform well as a student, meet deadlines and collaborate in a team creates considerable tension between efficiently achieving optimal outcomes in a team environment and learning [9]. The most efficient way to achieve high marks when the outcome of a project is the focus of assessment is for team members to align with tasks in which they are most skilled or experienced [15]. Consequently, students may not experience the breadth of learning opportunities within the program as they may feel continually pressured to limit themselves to one aspect of project management. For example, students who came into our program with little or no background in coding would delegate coding tasks to more experienced teammates. Skill level in coding has already been shown to vary by gender within undergraduate students, as boys engage in curricular and extracurricular coding experiences at far higher numbers in high school [16]. These early experiences have significant consequences for recruiting women to disciplines like computer and software engineering, which already have low numbers of women (approximately 15\% in Canada in 2017 [17]). With intentional curriculum design however, teamwork and project-based learning can increase self-efficacy and learning outcomes for minoritized groups [18].

\section{GENDER INEQUITY IN ENGINEERING}

The literature identifies four ways in which gender and teamwork interact to lead to inequities.

\section{Gendered beliefs about skill in communication}

Women are more likely to end up with more communications-rich roles (e.g. writing reports or acting as team leader), whereas men are more likely to end up in technically focused roles [3]. Both boys and girls believe that girls are better than boys at the language arts [19] Thus, men and women in a group may all believe that the women are more likely to be skilled communicators and will do the best job of report-writing and proof-reading, of taking minutes, doing presentations and chairing meetings. This is clearly problematic, since all engineers need to become proficient communicators.

In addition, it means that the woman members of a mixed team are less likely to take on technical tasks. Not only are they less likely to achieve the technical learning objectives, but since they have less practice, they (and their man teammates) become less confident in those essential building blocks and both skill and confidence are eroded through the rest of the program.

\section{Diversity takes planning and effort}

When students are given free reign over group formation, groups often form along culture or gender lines, reducing the within-group diversity that could lead to better problem solving [1], [2]. Diversity increases creativity, problem solving and financial results for companies [20], [21]. It does, however, take more effort to build trust in diverse teams. External, objective appraisals of team performance are more positive than self-appraisals [11]. Critically, diverse teams are more self-critical than homogeneous teams [11]. Srikanth et al. propose this occurs because team members encountered additional conflict and delays during project management [22]. These negative experiences encourage students to avoid conflict by working with colleagues with whom it takes less effort to build trust; those with similar identities. This means that students are not building skills around working within diverse teams and remain likely to avoid diversity in future hiring decisions.

\section{Strength in numbers}

When a student is the only woman on a team, her contributions are less likely to be valued, leading to feelings of exclusion or lack of fit; this is amplified in the absence of an ally [4], [5]. Being "solo" could remind women both of their gender, and of cultural expectations that engineering is a masculine domain. Women who choose to study engineering are aware that engineering has traditionally been a domain of male success and believe they need to perform at the highest level to represent their gender in the best possible light [23]. This could mean that they spend additional time polishing reports and ensuring that the final product is up to their high standards.

\section{Stereotype threat}

The experience of stereotype threat is defined by a fear of being judged according to or conforming to a stereotype [17]. However, this consequence of the threat is often maladaptive behaviours [17], [18]. Throughout their careers, employees who experience stereotype threat are less likely to engage in direct feedback-seeking behaviour, which can have detrimental consequences on career advancement [24]. Even when group members are welcoming, being the only person of a particular identity can highlight differences, which could activate stereotype threat [24]. For example, when engineering students were in a stressful test situation and were told that the results of the test were influenced by gender, women underperformed, compared to the treatment in which they were told that gender was not a factor [25]. 


\section{EQUITY THROUGH CURRICULUM DESIGN}

To achieve our goal of designing a project-based first year engineering course which teaches and rewards inclusive team behaviour, we looked to the significant literature in teamwork. We considered which methods would have a specific influence on inclusion and would fit within the constraints of our new course. We also initiated a set of focus groups with students (not discussed in depth in this paper), approved by the McMaster Research Ethics Board, to understand student experiences in the McMaster context. We have designed inclusive practices into the new course and are proposing some transferable recommendations for best practices for inclusive teamwork in engineering education. Specifically, we aimed to correct the effect of gendered beliefs about communication (and technical) skills; encourage diversity and inclusion in team formation; provide positive experiences for all students when sharing ideas and reduce the influence of stereotype threat, if not eliminate the stereotype of gendered views of engineering. The proposed curriculum will create more inclusive teamwork in a year-long project-based course in McMaster Engineering Year One through the following interventions:

1. Technical and non-technical roles will rotate.

2. Groups will be assigned and will be constrained to not have a gender-solo student.

3. Low-stakes, technically oriented icebreakers will accelerate trust-building.

4. Teams of students will receive formative feedback on team effectiveness, function and inclusivity

We began our literature review very broadly, by looking for factors that contribute to highly functional teams. We also targeted articles about education interventions that are designed to improve team function. Table 1 summarizes the types of teamwork interventions we assessed. The list is certainly not meant to be exhaustive, but it does cover many of the approaches to teamwork that have been described in the engineering literature. While all approaches had their merits (and we incorporating some to various degrees), we felt that the first four interventions listed best fit within our course constraints and had the most potential to ensure that all our students had equitable opportunities to achieve learning outcomes and experience an inclusive learning environment.

\section{Inclusive interventions: Rotating roles within teams}

Through the four sprint projects, each student will be assigned specific communications and technical roles. The goal of this intervention is to prevent students from being unintentionally segregated in roles, and as a result only achieving only a subset of the course learning outcomes [13].

Role rotation will occur for both technical and nontechnical roles. Within each sprint project, roles such as taking minutes will rotate weekly. Over the duration of the course, student will be required to take on at least three of four designated roles: team manager, administrator, coordinator and subject matter expert. Within those roles, each student will have to hand in a progress report that will be individually assessed. Additionally, Projects 2 and 3 will each have two coding and two computer-aided design modelling roles that students will be expected to rotate through. We recognize that it is not always appropriate to rather than integrate roles, but we believe this early attention to who does what will help break patterns created by identity and expose all students to new experiences. It has also been shown that groups run more smoothly and perform better when the role of team leader is rotated [14].

\section{Inclusive interventions: Assigning groups}

Different groups will be assigned for each project, maximising the opportunities for students to meet and interact. Group composition will be constrained so that there are no gender-solo students [26]-[28]. We recognise that other intersectional identities can contribute to "onlyness," but we are limited both in how many constraints we can apply and in gathering information about student demographic data.

To ensure that the constraints are met and that new groups can be created for each of the four projects, tutorials will be scheduled so that each group contains a minimum of eight women within the 40-student design studio (four projects, with the two women per group rotating each time). In the unlikely event that our overall gender balance does not allow this in every group, there might be all-man design studio groups. We remain concerned about the effect of other "solo" identities but are limited in the constraints we can address and our access to demographic information.

\section{Inclusive interventions: Icebreakers}

Given that building trust can take more time in groups of strangers, we are also incorporating teambuilding exercises [13], [29], such as low-stakes, technically oriented icebreakers for each project.

Team building exercises will be used to help facilitate group processes. Individuals have a greater sense of belonging and community when they have pre-formed relationships [30]. Each exercise was carefully designed so that it incorporated elements of the upcoming project without overwhelming students, giving them a chance to first get to know one another. We felt it was also important that these icebreaker exercises had perceived technical 
value to ensure that the students did not dismiss them as irrelevant.

\section{Inclusive Interventions: Feedback}

We are incorporating mid-project, qualitative, anonymous peer assessment, which will be followed by written personal improvement plans [31]-[33]. Lectures will include material on providing specific, constructive feedback, and on how to use feedback for continuous personal improvement.

The peer assessment intervention will use online tools to help students deliver feedback halfway through projects 2 and 3. The feedback will be set up in a questionnaire format with options for custom qualitative and quantitative fields. Instructors can control score release and monitor feedback for inappropriate comments.

An important component of this intervention is providing students with training on how to give and receive feedback to ensure that comments are helpful and appropriate, since unprofessional feedback can have more negative consequences on women [34]. Additionally, the questionnaire will contain an option for students to anonymously flag their group for help. If this happens, an instructor or teaching assistant will reach out to schedule a meeting with the group so that conflicts and other serious problems can be worked through with help. The goal of this intervention is to encourage inclusive group interactions and ensure that all students are being held accountable for their work and actions.

Students will be required to write personal reflections on how they plan to respond to the mid-project peer feedback.

Facilitating equity: Scheduling team-work and explicitly discussing inclusive teams in lectures

In addition to the four main interventions described above, we will provide additional support for students through scheduling dedicated project time and increasing awareness about the benefits of inclusivity.

From our focus groups, students highlighted the difficulties in scheduling team meetings outside of class time. Particularly for those who needed to commute (often those of lower socio-economic status), they felt frustrated by these barriers. The significant time allocated for design studios and labs will minimise this difficulty.

Just as we lecture on technical content, we will devote lecture time to describing best practices in inclusive teamwork, since this is an important learning outcome. We must do this carefully to ensure we do not incite backlash behaviour [35]. As in this paper, we will discuss the benefits and challenges of working in diverse teams, and the strategies to ensure optimum team performance.

\section{CONCLUSIONS}

Beyond the scope of this paper, we will continue to conduct focus groups and surveys with current students to test the effectiveness of these changes in future. By sharing these literature-based teamwork design principles, we hope to convince others to explicitly address identity-based inequities in engineering coursework.

Here are the best practices we recommend for inclusive teamwork in engineering education:

1) Devote time to teaching inclusive teamwork practices.

2) Designate technical and non-technical roles and ensure they are rotated between team members.

3) Assign groups that do not isolate students based on identity. This is most easily accomplished with gender.

4) Design technically focussed icebreaker activities to accelerate trust building.

5) Incorporate qualitative mid-project peer feedback with reflection.

6) Allocate in-class time for teamwork.

\section{Acknowledgements}

We wish to acknowledge funding from the McMaster University Faculty of Engineering "Educating the Engineer of 2020" fund and support from McMaster's MacPherson Institute Student Partner Program.

We want to thank Dr. Colin McDonald for encouraging us to be involved in developing this course.

\section{References}

[1] M. McPherson, L. Smith-Lovin, and J. M. Cook, "Birds of a Feather: Homophily in Social Networks," Annual Review of Sociology, vol. 27. Annual Reviews, pp. 415-444.

[2] R. (Celia) Pan, R. L. Shehab, D. A. Trytten, C. E. Foor, and S. E. Walden, "Barriers to Broadening Participation in Engineering Competition Teams," Jun. 2016.

[3] Lorelle A. Meadows and Denise Sekaquaptewa, "The Influence of Gender Stereotypes on Role Adoption in Student Teams," in 120th ASEE Annual Conference and Exposition, 2013, p. Paper ID \#6744.

[4] M. Thompson and D. Sekaquaptewa, "When Being Different Is Detrimental: Solo Status and the Performance of Women and Racial Minorities," Anal. Soc. Issues Public Policy, vol. 2, no. 1, pp. 183-203, Dec. 2002.

[5] L. Roberson, E. A. Deitch, A. P. Brief, and C. J. 
Block, "Stereotype threat and feedback seeking in the workplace," J. Vocat. Behav., vol. 62, no. 1, pp. 176-188, Feb. 2003.

[6] S. V. Rosser, "Group Work in Science, Engineering, and Mathematics: Consequences of Ignoring Gender and Race," Coll. Teach., vol. 46, no. 3, pp. 82-88, Aug. 1998.

[7] S. Hu and G. D. Kuh, "Diversity Experiences and College Student Learning and Personal Development," J. Coll. Stud. Dev., vol. 44, no. 3, pp. 320-334, 2003.

[8] V. Taras, J. R.-I. S. in Educational, and undefined 2007, "Effects of cultural diversity on in-class communication and student project team dynamics: Creating synergy in the diverse classroom.," academia.edu.

[9] M. Gerrard, K. Newfield, N. Asli, and V. C, “Are students overworked? Understanding the workload expectations and realities of first-year engineering," in ASEE Annual Conference and Exposition, Conference Proceedings, 2017.

[10] B. Galand, M. Frenay, and B. Raucent, "Effectiveness of problem-based learning in engineering education: a comparative study on three levels of knowledge structure," Int. J. Eng. Educ., vol. 28, no. 4, pp. 939-947, 2012.

[11] X. Gu, S. Chen, W. Zhu, and L. Lin, "An intervention framework designed to develop the collaborative problem-solving skills of primary school students," Educ. Technol. Res. Dev., vol. 63, no. 1, pp. 143-159, 2015.

[12] M. Buljac-Samardzic, C. M. Dekker-van Doorn, J. D. H. van Wijngaarden, and K. P. van Wijk, "Interventions to improve team effectiveness: A systematic review," Health Policy (New. York)., vol. 94, no. 3, pp. 183-195, 2010.

[13] R. S. Hansen, "Benefits and Problems With Student Teams: Suggestions for Improving Team Projects," J. Educ. Bus., vol. 82, no. 1, pp. 11-19, 2006.

[14] A. C. Alves, D. Mesquita, F. Moreira, and S. Fernandes, "Teamwork in project-based learning: Perceptions of strengths and weaknesses," Int. Symp. Proj. Approaches Eng. Educ., pp. 23-25, 2012.

[15] N. Boreham, "A Theory of Collective Competence: Challenging the Neo-Liberal Individualisation of Performance at Work," $\mathrm{Br} . J$. Educ. Stud., vol. 52, no. 1, pp. 5-17, 2004.

[16] J. McGrath Cohoon, "Perspectives on Improving the Gender Composition of Computing," Int. J. Gender, Sci. Technol., vol. 3, no. 2, pp. 525-535, Jul. 2011.

[17] "Canadian Engineers for Tomorrow | Engineers Canada." [Online]. Available: https://engineerscanada.ca/publications/canadian- engineers-for-tomorrow-2017. [Accessed: 14-Feb2020].

[18] P. Chen ${ }^{1}$, A. Hernandez ${ }^{2}$, and J. Dong ${ }^{3}$, "Impact of Collaborative Project-Based Learning on SelfEfficacy of Urban Minority Students in Engineering," J. Urban Learn. Teach. Res., vol. 11, pp. 26-39, 2015.

[19] I. Plante, P. A. O’Keefe, J. Aronson, C. FréchetteSimard, and M. Goulet, "The interest gap: how gender stereotype endorsement about abilities predicts differences in academic interests," Soc. Psychol. Educ., vol. 22, no. 1, pp. 227-245, Feb. 2019.

[20] M. Usher and M. Barak, "Team diversity as a predictor of innovation in team projects of face-toface and online learners," Comput. Educ., vol. 144, p. 103702 , Jan. 2020.

[21] V. Hunt, S. Prince, S. Dixon-Fyle, and L. Yee, "Delivering through Diversity," 2018. [Online]. Available:

https://www.mckinsey.com/ /media/McKinsey/B usiness Functions/Organization/Our Insights/Delivering through diversity/Deliveringthrough-diversity_full-report.ashx. [Accessed: 14Feb-2020].

[22] K. Srikanth, S. Harvey, and R. Peterson, "A Dynamic Perspective on Diverse Teams: Moving from the Dual-Process Model to a Dynamic Coordination-based Model of Diverse Team Performance," Acad. Manag. Ann., vol. 10, no. 1, pp. 453-493, Jan. 2016.

[23] E. Makarova, B. Aeschlimann, and W. Herzog, "Why is the pipeline leaking? Experiences of young women in STEM vocational education and training and their adjustment strategies," Empir. Res. Vocat. Educ. Train., vol. 8, no. 1, p. 2, Dec. 2016.

[24] L. Roberson, E. A. Deitch, A. P. Brief, and C. J. Block, "Stereotype threat and feedback seeking in the workplace," J. Vocat. Behav., vol. 62, no. 1, pp. 176-188, Feb. 2003.

[25] A. E. Bell, S. J. Spencer, E. Iserman, and C. E. R. Logel, "Stereotype Threat and Women's Performance in Engineering," J. Eng. Educ., vol. 92, no. 4, pp. 307-312, Oct. 2003.

[26] L. A. Meadows and D. Sekaquaptewa, "The Effect of Skewed Gender Composition on Student Participation in Undergraduate Engineering Project Teams," ASEE Annu. Conf. Expo., 2011.

[27] N. Dasgupta, M. M. Scircle, and M. Hunsinger, "Female peers in small work groups enhance women's motivation, verbal participation, and career aspirations in engineering," Proc. Natl. Acad. Sci., vol. 112, no. 16, pp. 4988-4993, 2015.

[28] M. Thompson and D. Sekaquaptewa, "When Being Different Is Detrimental: Solo Status and the 
Performance of Women and Racial Minorities," Anal. Soc. Issues Public Policy, vol. 2, no. 1, pp. 183-203, 2003.

[29] L. Kester and F. Paas, "Instructional interventions to enhance collaboration in powerful learning environments," Comput. Human Behav., vol. 21, no. 4, pp. 689-696, 2005.

[30] C.-W. Sheng, Y.-F. Tian, and M.-C. Chen, "Relationships Among Teamwork Behavior, Trust, Perceived Team Support, and Team Commitment," Soc. Behav. Personal. an Int. J., vol. 38, no. 10, pp. 1297-1305, Nov. 2010.

[31] L. E. Willcoxson, “It's not fair!': Assessing the dynamics and resourcing of teamwork," J. Manag. Educ., vol. 30, no. 6, pp. 798-808, 2006.

[32] M. Alizadeh et al., "Leadership Identity Development Through Reflection and Feedback in Team-Based Learning Medical Student Teams," Teach. Learn. Med., vol. 30, no. 1, pp. 76-83, 2018.

[33] B. Sridharan and D. Boud, "The effects of peer judgements on teamwork and self-assessment ability in collaborative group work," Assess. Eval. High. Educ., vol. 44, no. 6, pp. 894-909, 2019.

[34] N. J. Silbiger and A. D. Stubler, "Unprofessional peer reviews disproportionately harm underrepresented groups in STEM," PeerJ, vol. 7, p. e8247, Dec. 2019.
[35] T. N. Brannon, E. R. Carter, L. A. MurdockPerriera, and G. D. Higginbotham, "From Backlash to Inclusion for All: Instituting Diversity Efforts to Maximize Benefits Across Group Lines," Soc. Issues Policy Rev., vol. 12, no. 1, pp. 57-90, Jan. 2018.

[36] R. Or-Bach, "Design considerations for supporting collaborative modeling," in $3 r d$ IEEE International Conference on Advanced Learning Technologies, ICALT 2003, 2003, pp. 219-223.

[37] R. Maceiras, A. Cancela, S. Urréjola, and A. Sánchez, "Experience of cooperative learning in engineering," Eur. J. Eng. Educ., vol. 36, no. 1, pp. 13-19, 2011.

[38] M. A. Kousa, "Jigsaw cooperative learning in engineering classrooms," IEEE Glob. Eng. Educ. Conf. EDUCON, vol. 2015-April, no. March, pp. 58-62, 2015.

[39] A. Wong, C. McKey, and P. Baxter, "What's the fuss? Gender and academic leadership," J. Health Organ. Manag., vol. 32, no. 6, pp. 779-792, 2018.

[40] M. Webb, "Peer Interaction and Learning in Small Groups," in Peer Interaction, Problem-Solving, and Cognition, 2016, pp. 21-39.

[41] M. K. Bolton, "The role of coaching in student teams: A 'just-in-time' approach to learning," $J$. Manag. Educ., vol. 23, no. 3, pp. 233-250, 1999. 
Table 1: Approaches to teamwork described in the educational literature

\begin{tabular}{|c|c|c|}
\hline Intervention & Description & Refs \\
\hline $\begin{array}{l}\text { 1. Reassigning roles before course } \\
\text { completion (4.2 Rotating Roles) }\end{array}$ & $\begin{array}{l}\text { Provides the opportunity to work on multiple } \\
\text { skills within a single project. } \\
\text { Students must then teach their peers. }\end{array}$ & [13] \\
\hline $\begin{array}{ll}2 . & \text { Imposing constraints on group } \\
\text { composition (4.3 Assigning Groups) }\end{array}$ & $\begin{array}{l}\text { Create environments within groups that promote } \\
\text { learning and inclusion for all members. }\end{array}$ & [26]-[28] \\
\hline $\begin{array}{l}\text { 3. Implementing team building exercises } \\
\text { (4.4 Icebreakers) }\end{array}$ & $\begin{array}{l}\text { Allows group members to connect with one } \\
\text { another, important in facilitating group processes } \\
\text { and teamwork. }\end{array}$ & [13], [29] \\
\hline $\begin{array}{l}\text { 4. Peer assessment with summaries of } \\
\text { contributions (4.5 Feedback) }\end{array}$ & $\begin{array}{l}\text { Allows students to receive recognition for their } \\
\text { contributions to the group and encourages } \\
\text { honesty. } \\
\text { Instructors can identify groups that may need } \\
\text { extra help with group processes. }\end{array}$ & {$[31],[33]$} \\
\hline $\begin{array}{l}\text { 5. Initial learning based on current skill } \\
\text { set }\end{array}$ & $\begin{array}{l}\text { Beginners are given foundations to learn the } \\
\text { skill, while those with experience are given } \\
\text { problems that use their current skill set. } \\
\text { Allows all students to learn and be challenged } \\
\text { without advancing beyond others. }\end{array}$ & [29] \\
\hline $\begin{array}{l}\text { 6. Optional workshops on basic hard } \\
\text { skills }\end{array}$ & $\begin{array}{l}\text { Can focus on development of skills in a low- } \\
\text { pressure environment. } \\
\text { Gives students access to help outside of class } \\
\text { and office hours. }\end{array}$ & {$[36]$} \\
\hline 7. Jigsaw method & $\begin{array}{l}\text { Formation of expert and jigsaw groups (self- } \\
\text { report or objectively assessed). } \\
\text { Encourages interaction and collaboration } \\
\text { between team members as students must teach } \\
\text { their group members. }\end{array}$ & {$[37],[38]$} \\
\hline $\begin{array}{l}\text { 8. } \begin{array}{l}\text { Bonus leadership development } \\
\text { programs }\end{array}\end{array}$ & $\begin{array}{l}\text { Students are encouraged to go through } \\
\text { communication, leadership, inclusivity, etc. } \\
\text { training without being forced. } \\
\text { Incorporation of checkpoint questions. }\end{array}$ & [39] \\
\hline $\begin{array}{l}\text { 9. Continuous individual learning } \\
\text { assessments on all skills }\end{array}$ & $\begin{array}{l}\text { Encourages students to practice all skills listed } \\
\text { in learning outcomes. } \\
\text { Bonus /reward for groups where all members } \\
\text { perform above a certain threshold. }\end{array}$ & [40] \\
\hline 10. Problem solving frameworks & $\begin{array}{l}\text { Students provided with strategies for problem } \\
\text { solving to help them reach checkpoints more } \\
\text { effectively. }\end{array}$ & [11], [29] \\
\hline 11. The coach approach & $\begin{array}{l}\text { Guided conflict management and constructive } \\
\text { feedback } \\
\text { Helping teams with initial group processes. }\end{array}$ & [41] \\
\hline
\end{tabular}

